\title{
Culture Pedagogy: Some Theoretical Considerations
}

\section{Introduction}

In this chapter ${ }^{1}$ I will consider some of the underlying issues of language and culture pedagogy. Whilst it is the basic tenet of this study that language and culture need to be addressed in an integrated manner in language teaching, I will nevertheless discuss language and culture separately as two interlinking pedagogic areas.

In the first part of this chapter I look at views of culture which underpin culture pedagogy as part of modern language degrees, and I describe some of the practices. I argue that teaching culture as part of language classes may be better served by a 'cultural studies' approach, rather than courses which emphasise the 'content' dimension and focus on imparting knowledge about the target language country as a coherent overview. The latter approach tends to be located in a national view of language and culture, whereas a cultural studies approach focuses on the processes and practices of culture and the construction of meaning and allows for a more complex idea of culture.

In the second part of this chapter I focus on views of language in relation to culture which have influenced language teaching approaches. In doing so I argue that a traditional structural view of language as stable still underpins some contemporary language courses, and that this view has taken on a common-sense understanding. I then describe social and cultural views of language, including those derived from linguistic relativity, critical language study and Hymes' notion of pragmatic language use. 
I conclude the chapter by discussing how the two areas are interlinked in pedagogy.

\section{Teaching Culture}

\section{Views of Culture}

It is a 'truism' that the word 'culture' is problematic. Raymond Williams is purported to have said he wished he had never heard 'the damned word'. There are various common sense definitions of the word, and Williams's discussion on this is still a good place to start. As he points out, there are various overlapping categories of meaning: culture as a process, as a product and as a way of life of a particular community, but the meaning of the word shifts continuously (Williams, 1983 (1976). Stuart Hall (1997: 34-36) calls the word 'the new language of our time'; it is a catchword, used widely and frequently 'from politics to business, from life-style to media' to refer to the way people think, feel and behave. Frequently, the words 'social' and 'cultural' are used interchangeably, both in everyday use and in the literature on the subject. There are no clearly agreed definitions on what separates the social from the cultural, although the word social is more often used when we talk about structures and systems of society and relations between people or groups of people, whereas culture is often seen as encompassing anything social plus the wider notions of value and ideological systems.

In Williams' seminal book Keywords he lists the intricate and complex semantic transformations the term 'culture' has undergone since its early use in the $15^{\text {th }}$ Century. In summary, modern usage of the term relates to three broad categories (1983 (1976): 90):

1) a general process of intellectual, spiritual and aesthetic development. This usage captures the idea of culture as a natural process of human development in a linear way, the ultimate of which resulted in the European 'civilization' and culture of the Enlightenment. Culture is then seen as a universal development of human history;

2) a particular way of life, whether of a people, a period, a group or humanity in general, in short, the anthropological view of culture. The use of the word 'culture' as 'a way of life' started in the $18^{\text {th }}$ century with Herder (1782-1791) who attacked the Eurocentric view of culture encompassed in the first definition. This view contrasts with the first one, as it does not see culture as a universal process, but instead sees 'cultures' in the plural: 'the specific and variable cultures of different nations and periods but also of [...] social and economic groups within a nation' (Williams, 1983 (1976): 89). Whilst Herder is sometimes cited as being the fore- 
runner of the one nation, one language view of culture, he was, according to Risager, not a National Romantic (Risager, 2006: 61). The view of culture, in terms of specific particularities associated with a particular group of people, often equated with nation or ethnicity is a dominant one in common parlance. Generally speaking, these particularities refer to behaviour, belief systems, history, language, customs, values, and so on. Within cultural anthropology itself, however, this static view of culture is seen as outdated (cf. Wright, 1998; Street, 1993; Hannerz, 1999).

3) the works and practices of intellectual and aesthetic activities, such as music, literature, painting and sculpture, often referred to as Culture with a capital $\mathrm{C}$ or 'high' culture. In daily contemporary usage this view of culture now also includes products and practices from popular ('low') culture, such as film, tv and media. The use of the terms 'high' and 'low' indicate the value judgements attached to these. Hence, Eagleton represents the view of 'high' and 'low' culture as the 'culture wars' (Eagleton, 2000).

The latter definition, culture in the sense of aesthetic activities and products, is the view of culture which has been traditionally assumed in modern language degree programmes, at least in Britain. In the liberal humanist educational paradigm, culture was (and in certain institutions still is), mostly seen through the prism of the literary canon, the 'high' view of culture, which combines the aesthetic view with the hierarchical view of culture as civilisation. This concords with Matthew Arnold's (1889: 56) view of "the best knowledge and thought of the time". However, as I discussed in chapter 1, as a result of the expansion of university education in Britain and the political pressures towards instrumental aims of language learning, literature courses have been increasingly replaced by courses focusing on 'contemporary cultural studies', as Worton referred to it (2009), bringing about a change in how 'culture' is interpreted. 'Contemporary cultural studies' in Worton's report refers to courses which combine the 'high', and 'low' view of culture; literature as well as film studies. But in addition, culture is part of the curriculum in its anthropological form through 'Area Studies'. These courses tend to include the history, politics and social structures of the target country.

When it comes to the view of culture as anthropology, culture as a way of life, there is, however, a range of practice in courses taken as part of a modern language degree. At the humanities-based modern language degree programmes at the university where this study takes place, for instance, there is, for instance, no reference to the term Area Studies. Non-literature courses tend to be taught in academic disciplinary areas, such as history, film studies, and occasionally as linguistics or socio-linguistics. Increasingly courses are taught comparatively (e.g. comparing literature from different countries) or as interdisciplinary, thematic courses. 
Language teaching remains strictly separate from the 'content' courses. In this book, my concern is not with separate content courses in the academic disciplines of literature or history, but with the cultural dimension of language teaching itself. For this reason I will not discuss Area Studies as an academic discipline. What I will discuss is culture pedagogy as it is practised in the language classroom.

I start with the knowledge dimension of culture pedagogy, which is often underpinned by the national dimension of culture.

\section{Knowledge in Culture Pedagogy: Examples of Dutch Textbooks}

With the knowledge dimension, I am referring to courses which are, even if implicitly, based on a view of culture pedagogy which used to be called Landeskunde. This term is now gradually disappearing, as Risager says, (Risager, 2007: 5) but the idea of providing an overview of knowledge of society, country and culture, an extension of the old, what Risager refers to as 'landand-people tradition' (ibid: 27), still underpins many language courses in practice. The term kennis van land en volk (knowledge of land and people), is also in some cases still adhered to in the context of Dutch as a Second and as a Foreign Language. The term is gradually being replaced by Nederland-en Vlaanderenkunde (knowledge about the Netherlands and Flanders), a clear indication of the national orientation of this approach to culture in language teaching. The traditional 'land-and-people' courses took a strong orientation towards typical national characteristics (ibid: 28). This emphasis has changed over the years, yet the discussion of the 'national typical', even of the national psyche, was until recently part of many language courses. I will discuss this below in relation to some Dutch textbooks which specifically address the culture dimension, either as an integrated language activity, in providing reading texts in Dutch, or as articles written in English to be used by teachers to address 'culture' in the curriculum as they see fit.

The knowledge element of culture pedagogy, particularly when it has a strong national focus, tends to be based on a view of culture in terms of its particularities. These courses are based on the idea of a defined culture or 'cultures' (Williams, 1983 (1976): 89) that can be clearly described as a cohesive unit, marked off from the cultures of other groups of people (Risager, 2006: 33). The most traditional of courses in this mode focus on the history and social structures of the target country, providing factual information on, for instance, the party political, judicial, educational and healthcare systems, economics, media and historical events. In other words, a course that describes rather than analyses. These courses tend to provide a simplified picture of society in order to create a coherent overview. An example of a book which is used (or perhaps more 
accurately now, used to be used, at universities abroad where Dutch is taught is Nederland leren kennen (Snoek, 2000, (1996)). This consists of chapters focusing on history, culture, recent social issues, economics and religion written in Dutch and functioning as reading texts in the language classroom. Another, well-respected, example is The Netherlands in Perspective: The Dutch way of Organizing a Society and its Setting (Shetter, 2002 (1997), an English language resource providing an in-depth historical, social and cultural 'coherent overview of the Dutch society in all its aspects' [my translation] (Beheydt, 2003). Themes running through the chapters emphasise supposed national characteristics, such as the consensual nature of Dutch society, the pragmatic approach of its citizens and institutions and, above all, the insatiable need to 'organise'.

The kind of Landeskunde pedagogy I referred to above, might seem a little outdated, with its broad overview and its references to national characteristics. However, the national paradigm is anything but outdated, at least in practice. Courses which aim to provide a cultural dimension are more often than not presented in a national framework, and directed towards 'the target country' and 'the target language'. Some of these courses can indeed by very informative, aiming for deeper understanding of the cultural and social complexities of the country under study. Recently, in the Netherlands a book was published with the intention to address 'culture' in a more complex context, acknowledging that Dutch national identity is fluid and apt to change as a result of globalisation and multiculturalism (Besamusca and Verheul, 2010). Their book, Discovering the Dutch is not primarily written for the educational market, but already it has become a key text for Dutch language and culture courses at universities in and outside the Netherlands. This book takes a more contemporary approach to 'Dutch culture' than some of its predecessors I mentioned above. Gone are the references to national characteristics of the Dutch. And there where Dutch characteristics such as pragmatism and tolerance are mentioned, this is always within the context of representations made 'through foreign eyes'. The approach to Nederlandkunde in this textbook is not only aimed at giving factual information, but many of the themes which are touched upon are based on research and theoretical considerations. A chapter on the multicultural society, for instance, offers a gentle critique of the 'us and them' approach adopted by the Dutch government, and sets the discussion in a complex historical context. The occasional references to the 'construction' of national identity, indicates that the idea of national identity is not necessarily taken as a given. The book clearly pushes the genre of Nederlandkunde, but it does not constitute a new paradigm as it remains located in a national context. This is not surprising, since the context of Dutch language and culture pedagogy, including the materials and textbooks available, is influenced by the guidelines of the European Council, which I will discuss later in the chapter. But, probably more significantly, Dutch language and culture teaching is influenced by the current political context in the Netherlands. As a response to the brand of government supporting multiculturalism, which the Netherlands pioneered in the late 1970s, the political 
climate has veered towards a strong national outlook, which demands cultural assimilation of immigrants. These political views also had an effect on the public discourses about 'Dutch culture' and history, and the media frequently discussed the need to reclaim the Dutch national identity. In 2006 a canon of the history of the Netherlands was commissioned by the government in order to address the fact that many native Dutch do not have a sense of their national identity and history. The canon, widely used in primary and secondary education, sets out the 'significant events in Dutch history' that all Dutch citizens should be aware of.

The national model in language learning in the Netherlands is strong. Language learning materials construct a nationality which constitute what Billig (1995) refers to as 'banal nationalism'; the representation of nationality through seemingly harmless symbols, such as the orange dress of football supporters, tulips on t-shirts, weather reports with national maps, and indeed language when it is seen as a political and national, rather than a social construct. Banal nationalism feels 'natural', because it is part of everyday life and customs.

The national outlook in culture pedagogy does then not only have its source in earlier romantic notions of nationality, but is also influenced by contemporary political contexts. Nor is it only a characteristic of Dutch foreign language and culture pedagogy. As Stougaard-Nielssen argued, the same national outlook takes place in course materials produced in Denmark (2010).

\section{Critique of the Nationally-Based Knowledge Dimension}

The national outlook is gradually being replaced, at least in theoretical discussions of language and culture pedagogy, by notions of transnationality (Risager, 2007,) super-diversity (Vertovec, 2009) and the idea of the Cosmopolitan Speaker (Ros i Solé, 2013).

The view of culture as complex, fluid, changing and indeterminate, is now dominating the pedagogical literature, as the world is becoming increasingly interconnected in an age of globalisation and mobility. Kramsch (2002: 276) refers to the invention of the personal computer as the watershed of changing views about culture. Before the 1970's culture meant national culture; 'what peoples had and held in common', whereas now she says referring to Geertz (2000) 'there is a scramble of differences in a field of connections.' As Brian Street (1993) said in an often quoted paper: culture is not a noun, but a verb. Culture is not a static object, but a dynamic process of meaning making. Holliday (2004: 132) quotes Hall to refer to the meaning making aspect of culture. 'A national culture is a discourse', Hall says, 'a way of constructing meanings which influences both our actions and our conceptions of ourselves.' (Hall, 1996: 613). These discourses of nationalities as 'imagined communities' ( $\mathrm{cf}$ Anderson, 1983) are powerful and perpetuate the myth of national unity and national characteristics that many in a nation would share. Hannerz (1999: 
393-407) argues that the seeming self-evidence of 'cultures' as entities existing 'side by side as neat packages, [as if] each of us identified with only one of them, is a time-worn anthropological concept. Most of us, he states, have more complex lives which entail various cross cultural allegiances.

Most of us come into contact on a daily basis, whether face-to-face or virtually, with people with different cultural or ethnic backgrounds, with people with different ideas. As a result we have all become global citizens, who have become part of 'a larger global tribe' as Appiah calls it, where intercultural encounters are no longer the exception but the norm for many. Appiah (2006) uses the term 'cosmopolitanism' to indicate the complexities and multifaceted nature of these daily intercultural experiences. This challenges the traditional notions of 'identity'. It challenges the notion of 'national identity' as consisting of a clearly described and delineated set of fixed characteristics shared by all within the borders of a nation-state. It also challenges the traditional notion of individual identity - the idea of individuals having a core and stable self, which remains unchanging over time.

But the notion of 'cosmopolitanism' does not assume that we all share a universal set of values. The interconnectivity of intercultural encounters that globalisation brought, is only one aspect of 'cosmopolitanism'. It does not preclude the perception of the particularities of ethnic, cultural or national identities.

Kumaravadivelu (2008) proposes that our complex cultural and subjective experiences are formed by at least 4 different 'realities' of which the global one is only one aspect. The others are formed of national, social and individual realities. It is important to note that none of these realities should be seen as fixed itself. Instead, each of these shape and reshape one another in a dynamic and constantly shifting relationship (p.157-158).

However, as I showed above, in language learning materials, the national outlook remains strong. Textbook writers and teachers of 'culture' do face a difficult choice. On the one hand teachers want to emphasise the complex social and cultural reality of 'the target culture'. On the other hand, teachers or textbook writers do not want to create a confusing message to students; after all, it would be hard to deny that there are cultural specifities. Moreover, students often want to know about what makes 'the' culture of the country or countries whose language they study different from their own. Besamusca stated that her students were disappointed when they found out that certain practices in the Netherlands were similar to those in their own country. Students had hoped the Netherlands to be more 'exotic' (2006). Similarly, Ros i Solé found in her study in learner identities that students often are attracted to the language they study because of a romanticised idea of the culture (Ros i Solé, Fenoulhet, 2013). This pull between the pedagogic desire for clarity, and the intellectual desire for acknowledging complexity, is part of what Risager (2007: 216) calls the national dilemma.

The content dimension of nationally oriented courses which focus on imparting information tends to centre on sociological and historical themes. 
But there are two other areas which are also considered to be part of the cultural dimension of language teaching. Since Byram (1989) developed a model for intercultural communicative competence for what he used to call language-and-culture' teaching, the communication element has also become an integrated part of culture pedagogy. I will discuss this in greater detail in the next chapter. The other very significant element in culture pedagogy, apart from social, political and historical information, is the anthropological aspect of culture as everyday experienced life. This aspect has been included in the detailed taxonomy by the Common European Framework of References for Languages (2001).

\section{The Common European Framework}

The Common European Framework of References for Languages (CEFR for short) was commissioned by the Council of Europe and published in 2001. Even though it is to a large extent based on Byram's notion of intercultural communicative competence (see chapter 3 ), it cannot be completely attributed to him, as the CEFR is a consensus document between the various member states of the EU. In fact, as Risager points out, many of Byram's recommendations, particular those on intercultural competence, were not included in the final document (2007: 115). The CEFR provides guidelines for teaching, learning and assessment and does not suggest particular teaching methodologies. Instead, it consists of a taxonomy of the skills that learners should possess at certain levels of study. The CEFR arose as a consequence of the mobility schemes which were set up by the Council of Europe and which followed the removal of trade restrictions in the European market. These mobility programmes encouraged exchanges between staff in areas of governmental and non-governmental organizations in health, social care, education and other professional domains. To facilitate this movement, the CEFR was set up to encourage language learning, to provide parity in language provision across the EU to prepare people linguistically as well as mentally for the intercultural experiences that mobility would bring. It is an extremely comprehensive document which describes in detail what competences, skills and knowledges learners of a foreign language ought to possess at a particular level and in a particular domain.

The emphasis in the document is on language skills, although attention is also given to sociolinguistic aspects which stems from an instrumental rationale: one cannot be an effective 'intercultural' or 'cross-cultural communicator' without having at least a basic understanding of the social patterns and values in society as these are reflected in the way that people communicate. It relates to culture as communication. For this reason sociolinguistic information is provided to develop an awareness of prevailing communication strategies and customs (shaking hands when greeting, degrees of directness in expressing 
intent etc.). This is what Canale and Swain (1980: 30, 31) called 'sociolinguistic', 'strategic' and 'discourse' competence.

In addition to linguistic and sociolinguistic competences, there is a cultural dimension in the CEFR, which is referred to as 'intercultural awareness', although the emphasis is on language skills rather than on cultural aspects. An important aspect of this awareness is 'objective knowledge of the world' in respect of the country in which the language is spoken. This includes information about areas such as everyday living (e.g. food, hobbies, celebrations), living conditions (e.g. welfare arrangements), interpersonal relations (e.g. family structures, race relations, relations between genders), values, beliefs and attitudes, body language, social conventions (regarding, for instance, punctuality, gift giving, dress, and taboos), and finally ritual behaviour regarding, for instance, religious celebrations, birth and death, festivals and so on (CEFR, pp101-130).

Whilst the CEFR acknowledges that intercultural awareness should be seen in a wider sense than the context of the L1 and L2 cultures, it also emphasises that learners should be aware of 'how each community appears from the perspective of the other, often in the form of national stereotypes' (CEFR, p.103).

Even though the CEFR document does not make reference to its particular perspective on culture, the view which emerges from the CEFR seems to be partly based on a similar view of culture as underpinning Landeskunde: culture as knowledge. But its inclusion of attitudes and values with regards to a range of areas in daily life, suggests that Geertz's (1973) symbolic and interpretive view of culture as 'historically transmitted patterns of meaning [...] by means of which men communicate, perpetuate, and develop their knowledge about and attitudes toward life" (Geertz 1973: 89) may also have informed the CEFR.

The CEFR has undoubtedly advanced the notion of culture pedagogy as part of language teaching by introducing a considered list of the wider aspects of cultural knowledge that it considered students should possess. But in practice, at least in contemporary Dutch language courses (cf. Contact, 2010), the cultural dimension is limited to a few reading texts about topics such as the geographical situation of Flanders, or information about everyday habits such as customs and conventions regarding food or celebrations. The rest of the course is solidly based on a functional approach to language teaching; arguably a more considered inclusion of the cultural dimension of the CEFR would have been a step forward.

The focus on everyday life in the CEFR gives the potential to include an ethnographic element into language courses; a self-reflexive awareness of the political, cultural and social influences to which learners are subjected themselves in their everyday experiences and realities. However, this possibility is not emphasised and the CEFR's treatment of the cultural dimension of every day life is superficial. It does not encourage reflection beyond a comparing of everyday living practices with the learners' 'own' culture. A national perspective 
of culture is taken, which links the foreign language to an essentialised idea of 'the' target culture and does not allow for a critical understanding of the complexities of cultural realities such as power inequalities, differences in role or status and the 'lived experience' occasioned by the complex and fluid cultural identities and subjectivities of people. It tends to represent culture as homogenous and stable and reduces culture to facts and information. This can provide students with pragmatic and useful information, but it also brings with it the danger of reinforcing, or even creating, unchallenged stereotypical images.

Despite the influence it has on language teaching in Europe, Risager only mentions the CEFR in passing in her overview of language and culture pedagogy (2007: 143); 'its conception of the relationship between language and culture, and that between language teaching and culture teaching [in the CEFR], is unclear and without theoretical foundation', she states. Yet, the CEFR informs many language courses in Britain and seems a force to stay.

Whilst I think an element of knowledge about the target country needs to be addressed in language pedagogy, it should not present culture in a bounded, stable and one-dimensional way, as that will not provide the enabling of an intellectual critical development in the students. This brings us again to the issue of criticality.

\section{Criticality and Culture: My Own Considerations}

When I initially started to develop the Dutch language course on which this study is based in the mid 1990s, one of my prime motivations was to introduce an intellectual and critical element to the course. I discussed the motivations for this in the introduction. At the time, criticisms against a national approach had not yet arisen in the pedagogical literature, except as a rejection of the ultimate aim of language learning to emulate 'the native speaker'. The cultural content element of language teaching courses was largely limited to the national. My own discomfort with the national approach, honesty demands me to say, was at the time not theoretically motivated, but was the result of practical considerations. Wanting to introduce a critical element into language and culture teaching based on the practice of asking students to discuss intellectually stimulating topics, rather than only providing information, I found, unsurprisingly, that most topics relating to culture and society had international relevance. In discussing environmental issues, for instance, students would automatically introduce perspectives, angles and examples which were related to their own experiences, and to discourses with which they were familiarised through their own varied contexts of living. But rather than taking a comparative perspective, it soon appeared through these discussions that the discourses on which students, or the articles I presented them with, drew, were not limited to national situations or view points, but rather to global ones. The differences between 
perspectives were not informed by nationality, but by ideological and general worldviews which crossed borders.

So from starting out to address critical skills at the level of 'critical thinking', or questioning skills, which is located in a humanist educational perspective, I arrived through pragmatic considerations at, what Risager calls, the transnational perspective. I conceptualised this as 'global discourses', but since national political situations impact on global debates, I also conceived of the notion of 'national articulations' within these discourses. I will develop this idea further below.

What I had conceptualised at the time, was that culture, language and communication were infinitely more complex and fluid than most language and culture courses allowed, and that the criticality for which I aimed needed to go beyond the questioning skills of 'critical thinking. The criticality that was needed to understand how meaning is created, which discourses come into being, why and how, and generally to understand the processes of meaning making, demanded a different ontological view of culture pedagogy.

An information-based approach would not suffice. A better option for the language and culture teacher would be to address culture in terms of its wider definition, and see cultural products and practices in relation to the meaning making processes that inform them. I found this in the Cultural Studies approach.

\section{Cultural Studies: Context}

The term cultural studies needs explaining as it is used in different ways in different contexts. In modern language degrees the term is often used to refer to academic subject courses with 'cultural content', such as literature, film studies or area studies. In language pedagogy literature the term has also been used. In his 1989 book Byram called the language and culture pedagogy for which he started to develop a theoretical basis 'Cultural Studies'. However, his use of the term is not the same as that of the Cultural Studies movement which I discuss below. Byram has since dropped the term, as his overriding concept came to be the 'Intercultural Speaker', which I discuss in chapter 3.

I use the term cultural studies here in line with Turner (1992: 9) to refer to an interdisciplinary area of study - rather than one particular approach - where various concerns and methods converge which have 'enabled us to understand phenomena and relationships that were not accessible through existing disciplines'. Its interest encompasses a very broad field of contemporary cultural practices, products and processes, although its main focus tends to be on 'popular' culture, as it rejects the notion of the 'canon'. Whereas a Landeskunde approach focuses on providing information and knowledge, a cultural studies approach allows students to engage with texts, to 'discover' information about cultural practices, values or processes through reading and interpreting texts. 
In chapters 3 and 4 I set out my particular take on how to include a cultural studies approach in a language class, but below I provide a short overview of some of the main ideas and concepts associated with cultural studies as an approach to culture pedagogy.

\section{Overview of Ideas of Cultural Studies in Culture Pedagogy}

Cultural Studies developed initially in Britain. The Centre for Contemporary Cultural Study (CCCS), the first of its kind, was established in 1964 at the University of Birmingham. The birth of cultural studies marked a movement which took a very different view of culture than the traditional one, which is based on the literary canon, and regarded culture as a socially informed construct rather than purely the expression of an individual great mind. The distinction between high and low culture became irrelevant. Raymond Williams, generally considered to be the godfather of this movement, has been seminal in seeing culture as a process as well as 'concrete lived experience', and in analysing cultural products in relation to the institutions and social structures which produced them (Williams, 1961).

British Cultural Studies changed the way that people think about, study and teach culture, but as the approach developed beyond Britain, different interpretations underpinned by different theories, emerged. Much of British Cultural Studies was initially informed by a Marxist agenda, centring around issues such as power relations, particularly those determined by social class. Later academics, such as Stuart Hall extended the notion of inequality in society to incorporate areas of ethnicity and gender. An important moment in cultural studies was the adoption of Gramsci's (1971) notion of 'hegemony', which views the cultural domination of a particular group as being achieved through persuasion or consent. Submission to the dominant ideas is then partly a consensual undertaking. People submit to dominant views because these views have developed a taken-for-granted perspective. Power is then exercised not so much by a dominant group or ruling class imposing its will on other groups or people, but instead power is the legitimisation of certain ideas in becoming the norm. As Van Dijk (1993) states, we speak of hegemony when subtle forms of 'dominance' seem to be so persistent that it seems natural and it is accepted that those that are dominated act in the interest of the powerful. Behind this principle of hegemony, as Wallace points out (2003: 30), is the view that people in general are not aware of the operation of power, especially as embedded in language. The idea that language practices and conventions are invested with power relations of which people are unaware, is also the focus of a strand of language pedagogy, Critical Language Awareness, which I will discuss later on in this chapter.

The issues in cultural studies are wide and varied but a consensus concerns the extent to which, and the processes through which, cultural meanings are 
made and accepted, and are imposed upon or resisted by us. The central questions are therefore to do with ideology and power. The notion of ideology which is used in cultural studies is a complex one. The concept of 'ideology' is often traced back to a Marxist view which pertains to ideas of economic and cultural domination of the ruling class over the working class. As Wetherell (2001: 286) says, 'Marxist work on ideology was concerned with testing ideas and statements for their truth value, or their accordance with reality'. However, this early view of ideology has become superseded in cultural studies by other views which are based on notions of reality which are more complex and subtle.

Stuart Hall (1983) uses the term 'ideology' to refer to a framework of ideas and concepts to make sense of the world. This view of ideology as a belief system is the one which is used most frequently in the 'common sense' understanding of the term. The notion of 'ideas' as encompassing a belief system is, I think, given more subtlety through the concept of 'discourses' as used by Foucault, which explains how ways of thinking about a particular topic or slice of the cultural or social world can become so dominant that it 'infiltrates' people's mind and takes on the aura of 'truth'.

What thus becomes relevant for study is not just what products or practices are part of a particular way of life, but rather the meanings attributed to them. Quite how we interpret cultural products and practices, whether we see them as forms of self-expression or socially enforced meanings, as acts of resistance or incorporation, depends on the theoretical paradigm and underlying epistemology from which we approach the texts we study.

Interpreting texts then, is not just a matter of seeing how meaning is encoded, but it is a process of constructing the meaning of signs which must take account of the wider context in which the texts are produced and in which they are read and received, or how they are 'articulated' (Stuart Hall, 1985). Meaning is thus not fixed, as different meanings can be ascribed dependent on the position from which we approach the sign. Different people, in different contexts, with different ideological backgrounds and different individual histories, will interpret texts in different ways. The importance of looking at signs not merely from the viewpoint of text production but also of text reception is central to many contemporary cultural studies practices. One of the key issues in this respect is the notion of intertextuality. As Maaike Meijer (1996) argues, this goes beyond traceable references to other texts and should be interpreted in its widest sense as the whole of the social and cultural climate and conventions. The reader constructs the meaning of the texts through his/her knowledge of and experience with other texts and a whole network of conventions and discourses. In this way a text becomes what Meijer calls a 'cultuurtekst', a network of accepted ways of talking about a particular theme. Seeing a text as 'cultuurtekst' necessitates looking at the cultural and social environment in which the text is produced. The intertexts also provide a wider context through the other cultural phenomena and practices to which the text refers and the discourses on which 
it draws. Intertexts provide the cohesive structure through which text and context can be studied in relation to one another.

Culture in Cultural Studies is not an aesthetic view of culture, but an anthropological one. This, as Risager (2006: 49) says, is an extension of Geertz' interpretative view of culture as a system of meanings. Whereas for Geertz, she explains, an already existing meaning needs to be 'unearthed' from texts or practices, in a Cultural Studies approach the emphasis is on the creation, recreation and the attribution of meaning as part of a process of people in interaction or 'dialogue.' This, as well as the notion of 'cultuurtekst' are key aspects in my own pedagogy which I will discuss further in chapters 3 and 4.

\section{Language in Relation to Culture}

\section{Orientations Towards Language}

In this section of this chapter I want to address some of the theoretical positions from which language is seen in relation to culture and how these theories have been reflected in language teaching. Looking at this relationship assumes that there is an intrinsic link between language and culture. This view of an automatic link between language and culture needs to be problematised, and I will do so at the end of this chapter. Indeed, this link is now almost commonly accepted in the theoretical literature on language and culture pedagogy, even if, in practice, certainly in the case of Dutch language teaching, the inclusion of culture in course books is very haphazard, and the pedagogic activities frequently display a view of language as stable and autonomous.

I will first discuss this approach to language as being stable and autonomous. I discuss this here as part of a traditional approach to language learning, before looking at social and cultural views of language.

\section{Traditional and Linguistic-Oriented Approaches}

I will start by briefly backtracking to the traditional approach to language teaching in university language degrees. This pertained to an Arnoldian concept of culture (part of which survives in traditional universities) and incorporated two views of language concurrently. On the one hand, language had a central role to play in the conceptualisation of 'high' culture, so that language was valued for its historical, literary and aesthetic dimensions. On the other hand, language teaching was divorced from these ideals and instead emphasised the structural properties of language, in accordance with methodologies derived from teaching Latin (Cope and Kalantzis, 1993: 41-45). 
As a result, language, as it was conceptualised in language teaching, became separate from its original anchoring in those traditional philological degrees. This split between an aesthetic and a formal view of language was occasioned, I believe, by the two conflicting trends of thought about language which were current at the time and which Vološinov² (1996 (1973): 53) describes as individualistic subjectivism, rooted in historical views and concerned with human consciousness, and 'abstract objectivism', which considers language as 'completely independent of individual creative acts, intentions or motives'. The first trend emphasises the individual and creative aspects of speech. Vossler, as quoted by Vološinov (ibid. p. 51), formulates it like this: 'linguistic thought is essentially poetic thought; linguistic truth is artistic truth, is meaningful beauty' The link with an Arnoldian view of culture is easy to recognise. The second trend, known especially for its Saussurean interpretations, looks at language as a system, and, as Vološinov (ibid. pp. 67, 68) says, ignores the social function of language and fails to do justice to its changeable and adaptable nature.

These two opposing trends in linguistic thought remained separate within foreign language degree courses and offered a two-tier view of language within one and the same degree; on the one hand language as literature; on the other, language as grammar. Neither 'individual subjectivism', nor 'abstract objectivism' is easily married with the idea of a relationship between language and culture, if culture is interpreted as a meaning making process as part of the wider social environment and its value systems. Whilst a Saussurean view of language allows both for an individual as well as a social side of language, Saussure sees these two elements as separate. His view is complex, but I feel relevant to the language teacher as many of these concepts have taken on the aura of 'common-sense' assumptions (Kress, 1994: 170, 171), and have influenced views on foreign language teaching. Saussure's notion of langue as a system of forms represents the social aspect of language in the sense that the linguistic rules have been agreed upon by a speech community. Parole (the utterance) on the other hand, as the execution of speech, represents the individual choices the language user makes. In separating these two elements, Saussure (1973: 11) says we can at the same time 'separate 1) what is social from what is individual; and 2) what is essential from what is accessory and more or less accidental.' What is essential to Saussure is langue, the system passively internalised by the individual speaker. In this trend, as Vološinov (ibid. pp. 52-54) explains, 'the individual acquires the system of language completely ready-made'. There is no room for individual creativity, because the linguistic system is fixed. A Saussurean view has no time for social values as reflected in texts or utterances, and is not interested in language as constructing social reality. Structuralism sees language in terms of its formal properties and not its use. This approach remained de rigueur in language teaching until the 1960s when it was gradually replaced by methodologies informed by contextual and communicative concerns.

However, a Saussurean-based view of language has influenced language teaching in more than its view of grammatical correctness as a major criterion 
in teaching. Saussure's notion of language as a system of signs encoding meaning also continued to inform language teaching approaches. For Saussure, the sign consists of the signifier (the outward stimulus) and the signified (the mental construct which the signifier conjures up). The problem with applying these notions directly to language teaching lies in the two assumptions embedded in this conceptualisation of the signifier and signified. One assumption is that the relationship between signifier and signified is arbitrary, that there is no inherent link between form and meaning, but that this relationship is established by convention alone. The other assumption is that language as a system is stable, fixed and bounded; meaning is tied to form and exists independently of context (Kress, 1994: 171). In other words, language is seen as an autonomous system without any relationship to culture.

The point I would like to make - and to which Kress refers - is that if we do not think there is a motivated relation between words and meaning, then language users merely engage in recycling pre-existing meanings. Applying this notion to language teaching would lead to the conclusion that it is sufficient to teach these pre-existing meanings, whether as grammar, vocabulary or functional phrases, as has indeed been the case in functional approaches. Language teaching becomes then in effect a mere re-labelling, sticking a different label to the same concept. How can we then express individual meaning? Or, looking at it from the pedagogic perspective of reading, the consequence of this view is that the text entails a definite meaning which the reader needs to extract.

The implication of a Saussurean view for language teaching is that semantics is restricted to surface meaning and does not extend to underlying meanings, or using Halliday's term, its 'potential to mean' (cf Halliday, 1978). Much of language teaching reflects this stable view in the tendency to look at texts and use them as exercises in testing comprehension of the explicit meaning presented. Yet it is by looking at implied meanings and at what texts do not say, the significant absences in texts, the reading between the lines, that students can access the social and cultural as well as individual meanings, which are constructed in a text.

In short, the views of language, which were, and in some cases still are, in operation in traditional language degrees, i.e. on the one hand language as expression of individual and creative thought and on the other hand language as a system of formal rules, would not form a good basis from which to derive principles for language teaching. I will now turn to cultural and social views of language and argue that these do not necessarily negate the potential to express individual meaning. 


\section{Social and Cultural Views of Language}

\section{Hymes' Theory of Communicative Competence}

Hymes' view of communicative competence (cf. 1967; 1972) brought an anthropological understanding to language, as it provides a model for analysing a communicative event in its socio-cultural context. His model indicates the various parameters that govern communication in terms of what to say, when, to whom and how to say it, and with what intention. This set of parameters in its pragmatic, goal-oriented and functional aspects has served as a guide for language teaching since the 1980s. It formed the basis of the functional approach to language teaching (cf Wilkinson, 1976), which was developed further in the Threshold Levels (Van Ek, 1991) of the Council of Europe, the precursor to the Common European Framework, which I discussed earlier in the chapter.

This approach focused on language functions in a few specific domains of language use such as shopping, travel, house and home, food and drink. Language teaching for communicative competence reduced Hymes' notion of communication to a limited and fixed set of situational topics, through which the learner would encounter and practice communicative acts such as giving a warning, inviting someone or asking for help, within set domains using set phrases. Its focus became a goal-oriented view of language where limited features of the situational context were the principal determinants of the linguistic choices to be made.

Reducing language teaching predominantly to the context of situation limits the learners' understanding of the role that our social and cultural environment has to play in our language use. Considering the context according to set parameters assumes that the rules for social communication used in one situation are the same in all situations of that kind. Like the Saussurean tradition, it assumes stability of meaning. It ignores the unpredictability of communicative events and the individual choices we might make in our utterances to respond to the context. It could be argued that learners would at least need to learn the conventions used in certain communicative settings, but even in situations governed largely by conventions we have the freedom to act in accordance with those conventions or not. As Kress (1994: 176) argues, even a decision to conform is an act of choice, and as such involves a 'new production of the meaning of conformity'.

However, it is not only the limited interpretation of Hymes' $(1967 ; 1972)$ formulation of communicative competence view of language which is the problem. I believe that his model, whilst helping us to understand the very important role of the immediate context, or the context of situation, does not fully address the idea of the complexity of culture. Even though cultural conventions are addressed through the parameters of 'norm' (social rules) and 'genre' (arguably a social view of text), it does not question or consider the wider view of 
'context of culture', which consists of wider societal influences and ideological forces and discourses (Halliday, 1985). Hymes did consider ideology in his later work, which I will refer to in the next chapter, but that work did not have an impact on language teaching.

The two notions of context come from the anthropologist Malinowski (1884-1942). Kramsch glosses Malinowski's idea of 'context of situation' as the 'immediate physical, spatial, temporal and social environment in which verbal exchange takes place' (1998: 126). Indeed, this is similar to Hymes' parameters governing communicative competence. But in order to understand meaning more fully, one also had to take account of the context of culture, Malinowski argued, which, as Kramsch quotes Malinowski, means taking account of 'tribal economics, social organisation, kinship patterns, fertility rites, seasonal rhythms, concepts of time and space' (ibid. p. 26). Whilst this relates to a traditional anthropological and static view of culture, the idea of context of culture can include a poststructuralist view of culture. The aim of achieving communicative competence in language learning has now been replaced by the notion of Intercultural Communicative Competence (Byram, 1997). I discuss this in chapter 3.

\section{Sapir-Whorf}

A strong culture-bound view which stems from a cultural anthropological perspective of language, is the Sapir-Whorf hypothesis, first formulated by Whorf in 1940 (Whorf, 1956) which holds that language and culture are completely interwoven. The Whorfian hypothesis posits that language determines the way we think; the possibilities and limitations of our language structure our thought, so people see the world differently because of their language. This view borrows from the romantic idea of culture that there is a direct link between a particular language and the particular culture where the language is spoken. In the literature of Dutch language teaching, this close relationship is often stated. In her monograph, aimed at teachers of Dutch as a second language, Van der Toorn-Schutte (1997: 9) suggests that the reason that foreign language learners of Dutch struggle with learning the language is because, not having grown up in the Netherlands, they perceive the world in a different way. Referring to etymology, as well as to pragmatics, she gives examples or words, expressions, linguistic as well as functional aspects of language, which are 'culturally determined. Whilst van der Toorn-Schutte seems to hold on to a strong notion of the Whorfian hypothesis, Van Baalen (2003) and Van Kalsbeek (2003) who also both refer to Whorf, agree that language is culturally determined, although they see this in a weaker form; of language reflecting rather than determining culture. Nevertheless, they both hold on to the one language, one culture view. Van Kalsbeek particularly focuses on miscommunication to which she refers 
as 'culture bumps', whereas Van Baalen uses Wierzbicka's cross-cultural semantics to encourage students to look at the 'culturally determined norms and values embedded in words' [my translation] (ibid. p. 107). Examples of these are words such as vriend (friend), tolerant, and the supposedly untranslatable word gezellig which refers to 'cosiness' as well as to 'having a good time in company'.

The problem with using the Sapir-Whorf hypothesis to inform pedagogy and the assumption of a direct relationship between one particular language and one particular culture is that it does not acknowledge the complex social, linguistic and cultural realities of people's lives. Roger Andersen (1988: 83) suggests that an influence of language on thought is indisputable. I agree that language has an influence on our perception of the world. However, I see this relationship not as being between 'a' language and 'a' culture, but rather in the way we construct our world through discourses which are part of culture and which we encounter in our daily lives. I come back to this later in this chapter.

Whilst Andersen (ibid. p. 88) also critiques linguistic relativity because it ignores the fact that people have different experiences, both in social terms and in their relation to the natural world, he adds a critical angle. These different experiences of people are not necessarily haphazard, he says, but based on inequality, because social and material knowledge are not distributed equally. For this reason, he suggests, issues of power relations need to come into the equation when looking at questions of language and thought. Interpreted this way, the issue becomes an ideological one and bears on similar concerns to the questions asked by cultural studies - to what degree are we free to create our own meaning, and can we resist the dominant 'taken-for-granted' interpretations of text? These questions reflect a critical approach to language and culture, in critiquing how power is reproduced through language. I will discuss this view of language below.

\section{Critical Language Awareness}

Critical Language Awaress (CLA) is not a view of language as such, but a pedagogic approach. I include it nevertheless in my discussion of social views of language, because its critical approach, derived from influences such as Critical Linguistics (cf. Kress and Hodge, 1979), Critical Pedagogy (Freire, 1970), and Critical Discourse Analysis (CDA) (cf. Fairclough, 1989; Fairclough and Wodak, 1996) is part of a shift moving away from viewing language as autonomous, to a more "ideological' model with connections to media studies and a more grounded understanding of social processes' (Pennycook, 2001: 9). Its aim is emancipatory: to encourage social transformation through denaturalising ideologies that have become naturalised (ibid. p. 81). CDA studies focuses particularly on unequal relations as produced through conversations, e.g. doc- 
tor and patient interviews, such as who gets to speak about what and for how long (Fairclough, 1989: 43-47).

CLA, as the pedagogic wing of CDA, aims to promote an awareness in learners of how power relations and inequalities are produced and reproduced through language. There are various practices of CLA, although there is usually a strong focus on the use of text and reading (cf. Wallace, 2003). CLA pedagogies encourage students to look at the way that power is reflected in the use of particular conventions, what the conditions and motivations were of the producers of a given text and how texts positions readers or listeners in terms of their role or identity. It raises awareness of how through the use of language people can maintain or change power relationships.

This pedagogy was developed in Britain and is used in some English Language Teaching contexts, but does not seem to have made much impact on foreign language teaching. One reason for this might be that a pedagogy of critical language awareness does not fit in easily with the now dominant skills-based traditional approaches to foreign language teaching.

However, Critical Language Awareness approaches are also used to develop productive language skills, particularly writing. Romy Clark (1992: 134-137) argues that in the case of academic writing, for instance, students should be aware of the prevailing conventions within the academic community and should be able to apply them. But equally important is, as she states, a critical attitude towards these conventions; by challenging dominant practices, students can learn to produce alternative discourses and inscribe their own meaning.

This last point has potential for further development as a pedagogy in the foreign language classroom. It hinges on the dual aims of empowering the learner to recognise social meanings and to be able to employ these if needed, but also to allow for human agency to create individual articulations within established discourses. I describe elsewhere (Quist, 2013) how in an oral presentation, one of my students employed both formal conventions and consciously departed from these. She did so by adopting generally an informal tone, in order to ensure her 'audience, who she had imagined to consist of a range of different people representing hierarchical relations, felt all equally respected and included.

I borrow from CLA in my own pedagogy in the sense that I ask learners to look at how people in texts are positioned and represented. However, my pedagogy deviates from CLA in the sense that its primary aim is not to 'unmask power', but instead to recognize the complexities of discourses in texts. In doing so, I am more in line with O'Regan (2006) who critiques CDA (the theoretical precursor to CLA) for its 'unintended privileging of a final reading of the text'. O'Regan locates this predilection of CDA in its attachment to humanist values of reason and truth (2006:21). His concern with criticality is to query the truth certainties' and the 'truth claims' in texts (ibid: 17). Whilst his motivation is 
political, in the sense that it is critiquing the naturalising of discourses of power inequalities, it is also moral in its concern with tolerance, and social justice. His take on criticality is not located in the ideology critique of 'emancipatory modernism' (Pennycook, 2001), but in the poststructuralist critique which Pennycook refers to as 'problematising practice', which finds its practical application in 'discursive mapping. This brings us to a discursive view of language.

\section{Discourse and Power}

The term 'discourse' is central to many social sciences studies and takes on a range of meanings. Foucault offered a 'three dimensional' definition, as Kumaravadivelu (2007: 218) states. The first of these definitions relates to all language in use; i.e. all texts or utterances. The second one relates to 'specific formations of fields' such as the 'discourse of racism', or the 'discourse of feminism. The third definition, Kumaravadivelu says, extends beyond language to the 'sociopolitical structures that create the conditions governing particular utterances or texts. Discourse, then, relates to the entire conceptual world in which knowledge is produced and reproduced. From this perspective language is only one of the entities that construct discourse. Texts are generated by discursive formations or discursive fields of power and knowledge. These fields construct certain ways of understanding the world (within particular domains) which then take on the status of common sense assumptions. A discourse then provides a limited set of possibilities and structures of what can be said and how it can be said within certain domains.

The field of education may provide an example. Discourses prevalent when talking about Higher Education, for instance, are those located in the discursive field of liberal humanism or that of vocationalism. The former provides a way of thinking about education as well as a general shared understanding of society which prioritises the individual over the social, which focuses on the individual's development of rational and rigorous thinking, and which is seen as leading to a general improvement of a 'moral' society. We could also add that this constitutes an understanding of education from a largely western perspective. The discursive field of vocationalism on the other hand, constructs the value of education as helping students on the career ladder. To do so students do not need critical thinking, but practical skills. The implicit values relate to prosperity, ambition, business, booming economies and financial security rather than an individual's development of the 'mind'. These discourses are reflected in prospectuses of HE institutions.

However, it is also clear that prospectuses would not be written using only one of these discursive fields. As Kress points out (1985: 7, 8), discourses do not exist in isolation, but in larger systems of sometimes opposing and contradictory, or just different, discourses. As discourses tend to, what Kress calls, 'colonise' areas, i.e. to account for increasingly wider areas outside the initial 
domain, texts attempt to reconcile these 'contradictions, mismatches, disjunctions and discontinuities' to seamlessly interweave these different strands (ibid.:10). A university prospectus may therefore reflect both discourses of liberal humanism and vocationalism in a seamless fabric, interwoven with other strands such as those emphasising the discourse of 'community of the university', as well as those referring to comfort and pleasure. Indeed, I draw on a range of discourses in the field of education myself in this thesis, and not always explicitly so. It is difficult for an individual to think outside these discursive formations which determine to a large extent what we can think and say in particular domains.

Discourses then seem to be deterministic: to reduce the role of human agency and to limit the autonomous free-willed subject's ability to step outside these discourses. After all, according to Foucault, discourse produces knowledge and meaning. As Stuart Hall explains: 'physical things and actions exist, but they only take on meaning and become objects of knowledge within discourse' (Hall, in Wetherell et. al. 2001: 73). In other words, it would be difficult to see a particular situation or action from a different perspective or attach a different meaning to it, then the meaning which is, as it were, provided through discourse. Discourse then, guides how 'reality' is interpreted. Knowledge, as Hall (Hall, in Wetherell et. al. 2001: 75) explains, is 'always inextricably enmeshed in relations of power because it was always being applied to the regulation of social conduct in practice.' In this sense 'discourse' comes close to ideology, but I prefer the notion of discourse, like Foucault, to make it clear I reject the Marxist position which focuses mainly on class.

Instead of 'ideology', Foucault put forward the notion of 'regimes of truth', discursive formations which seem to become 'true' because 'knowledge, once applied to the real world has real effects, and in that sense at least, 'becomes true' (Hall, in Wetherell et. al. 2001: 76). Hall gives the example of single parenting. If everyone believes that single parenting inevitably leads to delinquency and crime, and single parents are being punished accordingly, 'this will have real consequences for both parents and children, and will become 'true' in terms of its real effects [...].'

However, I believe the individual is not trapped within discourses, because in living complex and mobile lives, we are exposed to a multitude of discourses on which we draw at any one time, and sometimes these are ambiguous, conflicting or overlapping. Moreover, as an educational approach, we can step outside a particular discourse, when engaging in what Pennycook (2001) calls 'discursive mapping' or 'problematising practice'. Through discursive mapping, students can become aware of how discourses operate in texts to produce this configuration of power and knowledge. This discursive mapping can consist of relating the text to one's own experiences, both in terms of other reading as well as in terms of one's own lived experience. Using this approach allows students to see culture not as a one to one relationship with language, but in relation to the cultural complexity of our contemporary globalised society. 


\section{Relationship Language and Culture: Generic and Differential}

To conclude the discussion on the different views of how language relates to culture, I have argued there is a close relationship between language and culture; not as a direct link between a national language and a national culture, but rather through the ideas, values, knowledge and power structures of discursive formations which are expressed through language. Risager has theorised this distinction (2006: 2-5) as the generic and differential levels at which language and culture relate. Language and culture in the generic sense are 'phenomena shared by all humanity'; phenomena which are part of social life. In this sense, language and culture cannot be separated. At the differential level, on the other hand, we talk about different 'languages', whether national, e.g. Dutch, French, German, or language varieties. At the generic level, language and culture are inseparable, Risager argues; at the differential level, however, they can be seen as separate, as 'a' culture does not necessarily conform to 'a' language.

This duality helps to conceptualise the complexity of the language and culture relationship. Pedagogically, I believe, the language class should address both these levels. On the one hand, we should address the critical understanding of discursive formations in culture and society as reflected in and constructed through discourses - this is the generic level. On the other hand the main task of the modern language class is still to teach students to speak, write and understand 'a' language - in other words to teach, in my case, Dutch at the differential level. Whilst this would include teaching the standard variety of grammar, it should also include different language varieties, genres and voices. Teaching at the differential level does not necessarily mean teaching a stylised, standardised and sterile form of the language. But the complexity lies at the generic level, where I interpret the pedagogic activities to involve more awareness raising exercises and critiquing rather than actually teaching 'discourses', although, as I will discuss in chapter 4, part of my pedagogy is to get students to write for different purposes drawing on different discourses.

Discourses transcend the differential and national levels. In the contemporary world, many discourses are global, or at least extend across wide geographical areas. Examples are the discourses of 'terrorism', or 'environmentalism', or 'multiculturalism'. But, sometimes these discourses have a national accentuation. With this I mean that due to social or cultural histories and experiences of nations, as part of their nationhood, discourses may be 'articulated' differently in different places and contexts. One of these contexts is a national one. With this I do not suggest the existence of essentialised national discourse, but instead I argue there may be, in my case, a Dutch, articulation in texts, as one of the layers of meaning. 


\section{Dutch Articulation}

Discourses reflect largely meaning making practices which cross borders and are not limited to particular nations. This is the generic level where language and culture relate. However, due to historical processes and structures in society, which are formed along national lines, such as governments and educational systems, globalised discourses may take on a national 'articulation'. This has nothing to do with how people behave and think as a group and what characteristics they have, but it relates to accentuations of discourses which are deemed to be more common or more acceptable in certain social and cultural environments, including national ones. Similar articulations could just as easily exist in other countries or cultural groups, but if these accentuations are validated through the media in one country and not, or less so, in another, maybe we can talk about a 'national' articulation. The idea of a 'Dutch articulation' then became part of my idea of 'cultuurtekst'; as a nationally articulated 'flavour' or 'taste' of a particular globalised discourse. I use this as one aspect of my approach to analysing texts in the classroom (see chapter 4).

An example of Dutch articulation, as I saw it, is found in the Men's Health text, which I used for the data collection lessons; it drew on a discourse of gender roles and domesticity which, in my view, would not have been acceptable in Britain, nor indeed now, 10 years later, in the Netherlands itself. This discourse, exaggerated as it was in places, was made acceptable through the way it was interwoven with other discourses into a 'seamless fabric' (cf. Kress, 1985).

I know, I am treading on dangerous ground, as, keen as I am to emphasise complexities of culture, the idea of a Dutch articulation could be perceived to be an essentialist view. However, I do not see this notion as directly linked to 'a' national culture, but merely as shifting tendencies. This articulation is in itself continuously changing, shifting and contested. In chapter 4 I describe my interpretation of the Dutch articulation of the text which I used for my classroom data.

\section{Summary and Conclusion}

Central to this chapter is the concept of 'culture'. I argued that knowledge based language courses with a national bias do not provide insight into the complexity of culture, although when taught at an academic level, it can develop a critical understanding of the target country in terms of querying information given and understanding changing events in relation to the wider global and cultural situation. A cultural studies approach to culture in language teaching allows for acknowledging the cultural complexity and indeterminacies of contemporary life. 
I discussed various views of language and argued that the view of language as being stable and autonomous, as it is in the structuralist paradigm, leaves no role for cultural or social context. This view, whilst widely considered to be outdated in modern language teaching, still, unwittingly, underpins language courses.

Social views of language include the determinist Whorfian hypothesis, which is frequently quoted in the field of Dutch language teaching, to theorise the unrefuted relationship between language and culture. Whilst I believe there is indeed a strong relationship between the two, this is not at the level of ' $a$ ' particular language in relation to 'a' particular culture, which the Whorfian hypothesis supposes. Instead, this relationship is occurring at the generic level.

A more complex view of language and the social world underpins Critical Language Awareness approaches, which provide a critical stance and deepen learners' understanding of the processes of producing texts, and the ideological forces that have a bearing on this. CLA particularly focuses on how power is produced and reproduced through language. These approaches could be applied to modern language teaching, but the critical understanding, which is occasioned through CLA approaches, should be supplemented with an understanding of other cultural parameters, in addition to power.

Hymes' view of communicative competence provides such a view in considering a range of parameters, including time, place and social conventions. However, this view focuses primarily on the context of situation and does not allow enough space for the wider cultural ideas provided through the context of culture. Finally I argued that looking at language as discourse, and its meaning making potential, can help students to develop a deeper understanding of the complexities of the cultural world in which the language under study is spoken.

Risager's concepts of a generic and a differential level of language and culture help in considering how the notion of discourses can be conceptualised in relation to language teaching. I argued that both levels, the generic and the differential are part of language teaching, and the generic level avoids the narrow one-to-one relationship of the one language, one culture view.

Looking at language as discourse, Pennycook points us to pedagogies of 'mapping discourses' (2001), which helps to understand the multiplicity of discourses, how discourses cross borders, and develops students' critical awareness of how texts construct truth claims. Despite my focus on the global aspect of discourses, I also argued, that we cannot deny particular national 'accentuations', even if these articulations themselves need to be understood in the context of the complexity of culture in an age of mobility.

Finally, through discursive mapping students are invited to think about the relations and interrelations which are part of the process of communicating in different cultural situations and realities, and ultimately practise them.

It is this aspect of intercultural communication, which has been implicit in this chapter, which I will discuss explicitly in chapter 3. 


\section{Notes}

${ }^{1}$ Some parts of this chapter were previously published in Quist, G. (2000) Culture in the University Language Curriculum. Dutch Crossing (24), 1.

${ }^{2}$ The book is widely believed to have been written by Mikhael Bakhtin, using Volosinov's name. 